Nova Southeastern University

Florida

NSUWorks

NOVA SOUTHEASTERN

UNIVERSITY

\title{
Modern Biological Approaches to Folk Medicines and Traditional Antifungal Therapies
}

\author{
Matthew G. Jessulat \\ Carleton University \\ Robert P. Smith \\ Nova Southeastern University; Carleton University, rsmith@nova.edu \\ Nadereh H. Mir-Rashed \\ Carleton University \\ Golshani Ashkan \\ Carleton University \\ John Thor Arnason \\ Carleton University
}

See next page for additional authors

Follow this and additional works at: https://nsuworks.nova.edu/cnso_bio_facarticles

Part of the Biology Commons, and the Genetics and Genomics Commons

\section{NSUWorks Citation}

Jessulat, Matthew G.; Robert P. Smith; Nadereh H. Mir-Rashed; Golshani Ashkan; John Thor Arnason; and Myron L. Smith. 2006. "Modern Biological Approaches to Folk Medicines and Traditional Antifungal Therapies." International Journal of Technology, Knowledge and Society 2, (2): 171-180.

https://nsuworks.nova.edu/cnso_bio_facarticles/11

This Article is brought to you for free and open access by the Department of Biological Sciences at NSUWorks. It has been accepted for inclusion in Biology Faculty Articles by an authorized administrator of NSUWorks. For more information, please contact nsuworks@nova.edu. 


\section{Authors}

Matthew G. Jessulat, Robert P. Smith, Nadereh H. Mir-Rashed, Golshani Ashkan, John Thor Arnason, and Myron L. Smith 


\section{The International JOURNAL TECHNOLOGY KNOWLEDGE \& SOCIETY}

\section{Modern Biological Approaches to Folk Medicines and}

Traditional Antifungal Therapies

Matthew G. M. Jessulat Robert Phillip Smith Nadereh H. Mir-Rashed Ashkan Golshani John Thor Arnason Myron L. Smith

VOLUME 2 


\section{INTERNATIONAL JOURNAL OF TECHNOLOGY, KNOWLEDGE AND SOCIETY}

http://www.Technology-Journal.com

First published in 2006 in Melbourne, Australia by Common Ground Publishing Pty Ltd www.CommonGroundPublishing.com.

(C) 2006 (this paper), the author(s)

(C) 2006 (selection and editorial matter) Common Ground

Authors are responsible for the accuracy of citations, quotations, diagrams, tables and maps.

All rights reserved. Apart from fair use for the purposes of study, research, criticism or review as permitted under the Copyright Act (Australia), no part of this work may be reproduced without written permission from the publisher. For permissions and other inquiries, please contact <cg-support@ commongroundpublishing.com>.

ISSN: 1832-3669

Publisher Site: http://www.Technology-Journal.com

The INTERNATIONAL JOURNAL OF TECHNOLOGY, KNOWLEDGE AND SOCIETY is a peer refereed journal. Full papers submitted for publication are refereed by Associate Editors through anonymous referee processes.

Typeset in Common Ground Markup Language using CGCreator multichannel typesetting system http://www.CommonGroundSoftware.com. 


\title{
Modern Biological Approaches to Folk Medicines and Traditional Antifungal Therapies
}

\author{
Matthew G. M. Jessulat, Carleton University, Canada \\ Robert Phillip Smith, Carleton University, Canada \\ Nadereh H. Mir-Rashed, Carleton University, Canada \\ Ashkan Golshani, Carleton University, Canada \\ John Thor Arnason, University of Ottawa, Canada \\ Myron L. Smith, Carleton University, Canada
}

\begin{abstract}
The need to develop new antimicrobials is at the forefront of medical research. The notion of isolating novel antifungal drugs from plant sources has become increasingly popular. The approach of using ethnobotanical information to identify compounds with antifungal activity is of particular interest as these remedies have been used by traditional healers for thousands of years with little or no adverse side effects. Although once a laborious task, the separation, identification and determination of mode(s) of action of plant-derived antifungals has now become more rapid and efficient due to several new advancements in technology. Novel assays to determine the effect(s) of plant extracts on components of metabolic pathways are being developed. Large-scale methods to examine the pathways affected or cellular responses to a drug's presence such as GDA (Gene Deletion Arrays) and DNA microarrays, and the limitations of such techniques are critically examined. Coupled with analytical chemistry techniques, array-based bioassays are important for high-throughput modern drug research. Due to the enormous diversity of plant sources that may yield antifungal drugs, a database accessible to the scientific community containing traditional healer identified plants is recommended to increase the amount of research into new antifungal drugs.
\end{abstract}

Keywords: Antifungal Drugs, Microarray Analysis, Genome Arrays, Traditional Medicines

\section{Introduction}

$\mathrm{A}$ LTHOUGH SEVERAL ANTIFUNGAL drugs exist, new antifungals are needed since the incidence of drug resistant pathogenic fungi appears to be increasing [1]. In part, this increase may be due to increases in numbers of patients with compromised immune systems, such as individuals undergoing chemotherapy and AIDS patients, that may provide an infection corridor into the human host. However, fungi have a long history of causing animal, including human, mycoses and the reliance on relatively few antifungals has likely also selected for resistant pathogens. Therefore, as is true for antimicrobial compounds in general, the need to identify novel antifungals is of high priority.

For centuries, plants or plant derivatives have been used in traditional medical treatments. For example, eastern North America is host to roughly 400 species that have been used by First Nation's peoples as traditional medicines [2].Plants with a history of traditional uses in treating infections for more than 50 years, which produce few adverse reactions and have no toxicological problems, are suitable for development as natural health products (NHPs) in jurisdictions such as Canada and Australia. Alternat- ively, if intellectual property issues can be resolved, they may provide effective leads towards the discovery of new antifungal drugs. As fungi and animals are phylogenetically closely related, identifying NHPs and drugs that specifically target fungi is difficult. Many compounds that appear to be excellent fungal inhibitors are toxic to humans and are therefore not fit for consumption [3].

With the advent of new and improving technologies, the evaluation of plant-derived antifungals has become more rapid and efficient. The discovery of new plant-derived antifungal and antimicrobial NHPs or drugs could potentially have an enormous impact on health care in both developed and developing countries. This paper will detail the process, benefits and the technological aspects of discovering new plant-derived antifungal medicines. The present paper deals with methods to identify chemical components and evaluate their effectiveness as antifungal agents, as well as methods to determine a drug's mode of action in inhibiting fungal growth.

INTERNATIONAL JOURNAL OF TECHNOLOGY, KNOWLEDGE AND SOCIETY, VOLUME 2, 2006

http://www.Technology-Journal.com, ISSN 1832-3669

(c) Common Ground, Matthew G. M. Jessulat, Robert Phillip Smith, Nadereh H. Mir-Rashed, Ashkan Golshani, John Thor Arnason, Myron L. Smith, All Rights Reserved, Permissions: cg-support@commongroundpublishing.com 


\section{An Ancient Tradition and Modern Approaches}

The concept of utilizing plants as remedies for medical ailments and drug leads is a proven technology. Thousands of papers on antimicrobial activity are found in the published literature. Often, however, plant derived remedies are not catalogued in easily accessed literature, making selection of candidate plant species for development of ethical therapeutic products challenging. Many ethnomedicine practices that utilize plants are still passed on by oral tradition and direct communication with traditional healers is required to identify useful leads [4]. Is traditional knowledge useful in the discovery of antifungal agents? A study by our group [5] on medicinal plants utilized by eastern Canadian First Nations Peoples found that plants that were mentioned most often by traditional healers for conditions that have a fungal origin had both the highest overall antifungal activity and inhibited the growth of the largest proportion of different fungal species (Figure 1). This strong positive correlation demonstrates that traditional knowledge and modern science can come to similar conclusions. Traditional knowledge rationalizes the selection of candidate plants. Similarly, a study conducted on the antimicrobial activities of bark extracts isolated from eastern North American hardwood trees showed that those most used by First Nations Peoples tended to have the highest antifungal activities [6]. When extracts from wood and bark were compared, bark extracts showed higher amounts of antifungal activity. That bark is preferred over wood by traditional healers shows an understanding of which plants to select as well as which plant parts are most effective for therapy. In addition, it is likely that healers learned to select plants with the least severe side effects. Because of this, natural health products, such as plant-derived antifungals with a 50 -year history of safe use, can obtain regulatory approval in several jurisdictions [7].

Intellectual property rights are an important aspect to consider where traditionally used plant materials are concerned. International treaties such as the 1992 Biodiversity Convention recognize the right of countries (and indigenous groups) to control the use of their biodiversity. However, rather than complex compensation agreements which are difficult to negotiate and implement, people in developing countries need urgent assistance in the development and improvement of ethical antifungal NHPs for AIDS related infections. Besides traditional medicine, other rational approaches can lead to antifungal discovery in plants. Selection of taxa from very wet environments where fungi are prevalent, such as the Pacific slope of Central America, led to the discovery of some novel antifungal sesquiterpenes in a rare rainforest tree, Pleodendron costaricensis [8]. These substances are effective against several species of fungi including multidrug resistant forms of Candida albicans.

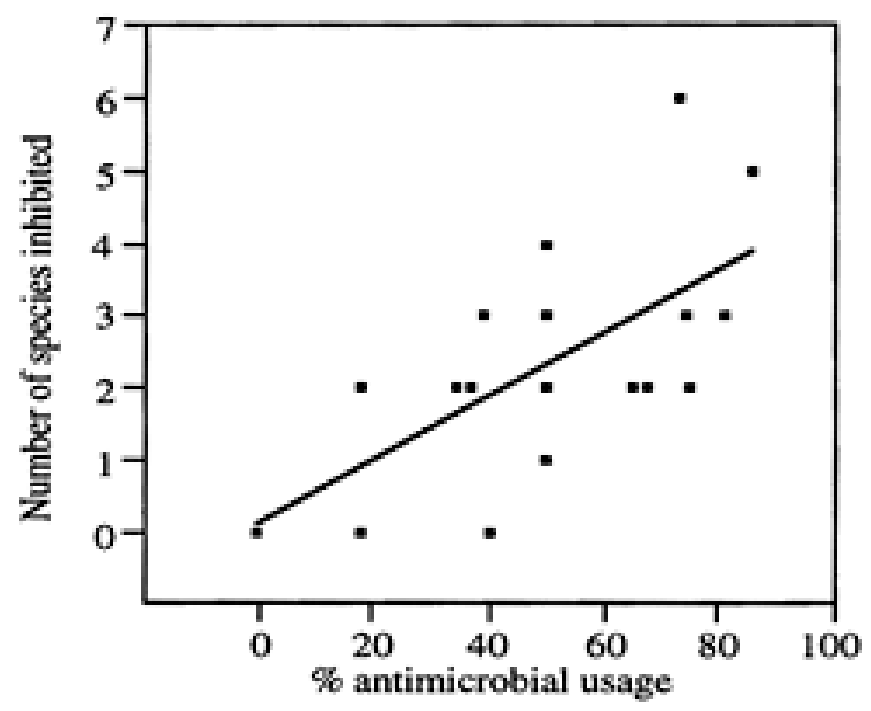

Figure 1: Efficacy of Traditional Knowledge. A strong, Positive correlation is observed between the numbers of different Fungal Species inhibited by extracts of Plants and the frequency of recorded Antimicrobial usage for same Plant by First Nations Peoples in Eastern Canada. Figure is adapted from Jones et al. (2000) [5] 


\section{Antifungal Resistance and Emergence of Opportunists}

The apparent increase in incidence of drug resistant fungal strains calls attention to the need for new antifungal drugs [1]. To acquire drug resistance, fungi, as well as other microbes, may implement several different changes. Mutations may be selected that increase activity of $\mathrm{ABC}$ transporter pumps to rapidly export unrecognised substances, or xenobiotics, from the cell [9]. Similarly toxin metabolism via cytochrome P450s and phase 2 metabolism may be altered in resistant fungi. If a particular antifungal inhibits a specific enzyme function, mutations may be selected such that the antifungal can no longer interact with the protein and enzymatic function is not compromised. Similarly, if an antifungal alters a cellular function so that toxic substances increase within the cell, the cell may alter its global metabolism to by-pass the effected pathway and eliminate the toxic substance using an alternate route [3]. For example, azoles are a widely used group of antifungal drugs that target ergosterol. Ergosterol, a functional analogue of cholesterol that occurs in the fungal cell membrane, is not found in animal cells making it a prime target for antifungals. Recently, however, several fungal strains have shown resistance to azole drugs through various mechanisms, including mutations in the ergosterol biosynthetic pathway that eliminate the azole target [10]. Several plant-derived antifungals are effective in inhibiting azole-resistant Candida strains including extracts from ginger (Zingiber officinale), and Echinacea pallida, a plant popularised in Western society that was originally used by First Nations Peoples in North America to treat sore throat, mouth and septic ailments [11,12].

The development of new antifungals not only applies directly to human infections, but also has potential to effect human well-being indirectly. For example, the presence of fungi in food and indoor environments is of increasing concern [13] and plantderived antifungals may have potential use as fungistatic or fungicidal agents in these areas. For example, Fusarium species are associated with widespread crop losses worldwide, mycotoxin production and human mycoses. Many strains are resistant to widely used antifungals [14] but several plantderived antifungals have been identified that are active against Fusarium species, including extracts obtained from Alpinia galanga, used by traditional healers of the Kenyah tribe in Borneo [15]. Isolates from the seeds of Syzygium jambolanum, a plant used by traditional healers in India, Malaysia, Australia and Ceylon, showed high levels of antifungal activity against a range of fungal pathogens and opportunists, including Aspergillus fumigatus [16]. Since many other examples such as those detailed above exist, the overall effectiveness of plant-derived antifungals in inhibiting unwanted fungal growth is promising.

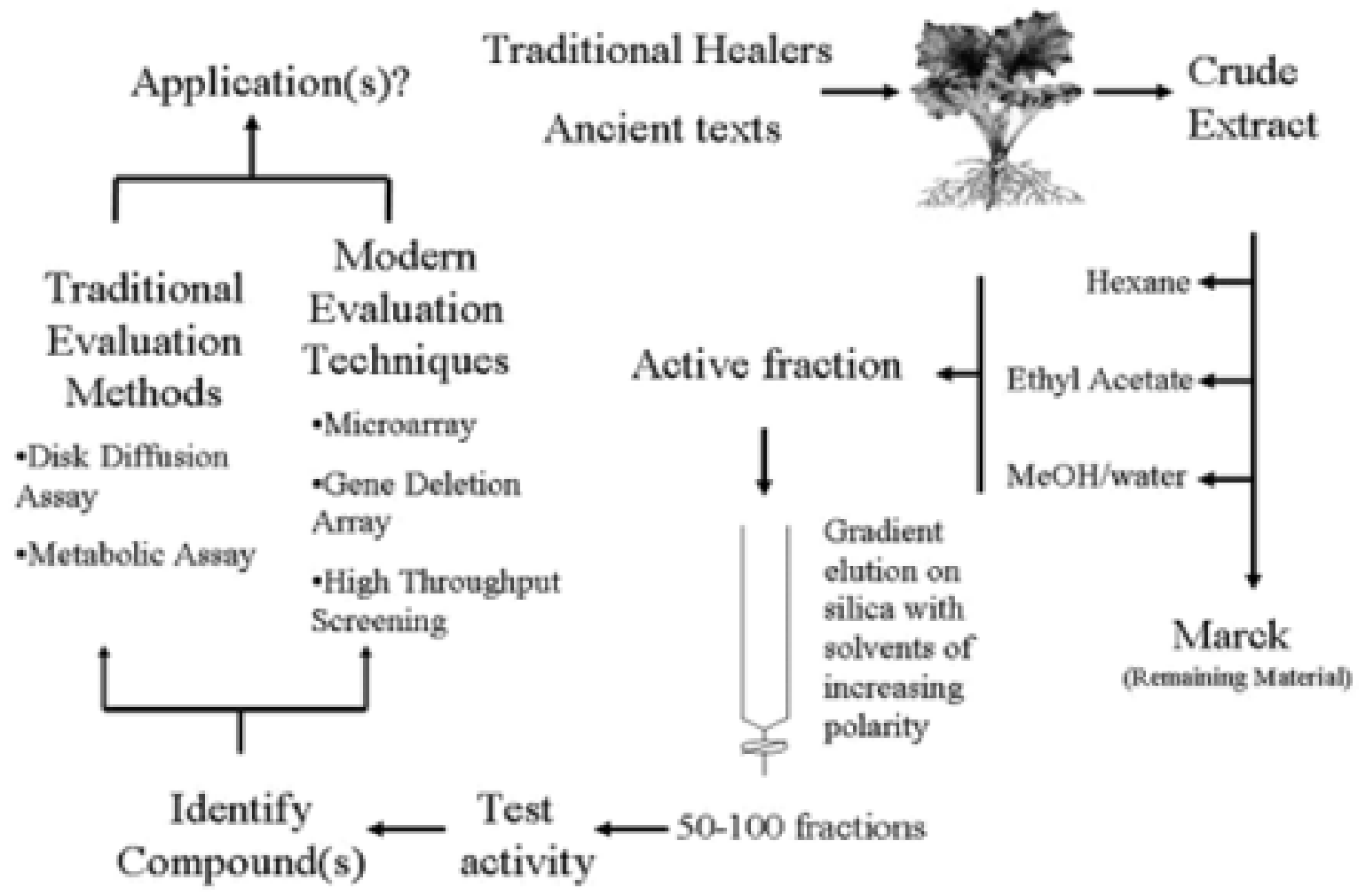

Figure 2: An Overview of Antifungal Drug Discovery from Plant-Derived Sources Based on Traditional Phytomedicine Leads 


\section{Advantages of Using Plant-Derived Antifungals}

Several advantages exist for using plants as a source of antifungals compared to drug development from a molecular perspective. Plants produce antifungal and antimicrobial agents as secondary metabolites in part to protect themselves from pathogens [17]. As fungal invaders circumvent secondary metabolites, plants must develop new protection systems. Since this arms race has continued for millions of years, the number and variety of antifungals synthesized by a plant species can vary. For example, Echinacea species likely contain a combination of acetylene and acetylenic isobutyl amides with diverse antifungal activities [18]. An understanding of these antifungal mechanisms employed by plants may lead us to new antifungal analogues and control strategies. Of particular interest, due to intense plant-fungal interactions, some plant species have likely evolved strategies to inhibit fungi that are difficult to overcome by resistance mechanisms, although this hypothesis remains to be tested.

To overcome resistance mechanisms, plants possess phytochemical diversity and redundancy so that secondary metabolites may have multiple cellular targets or they may contain multiple antifungals that target different systems. For example, extracts from Virola surinamensis yielded 9 different inhibitors of fungal growth (phytochemical diversity) [19]. Although the exact mechanisms by which these chemicals inhibit fungal growth are unknown, it is presumed that not all will target the same biochemical process in the fungus. A suite of analogous antifungals (phytochemical redundancy) that affects multiple targets may be difficult to overcome by a simple mutation in a fungal pathogen and the likelihood of developing resistance may be minimized.

Synergistic interactions, where two or more secondary metabolites work together to enhance activity, are also likely common in plants. Synergy is difficult to identify using current technology but can be extremely effective. For example, the medicinal plant Berberis fremontii contains the effective antifungal, berberine, and the synergist, 5 '-methoxyhydnocarpin [20]. It is postulated that 5 -methoxyhydnocarpin inhibits xenobiotic pumps and thus enhances the efficacy of berberine. Since activation of xenobiotic pumps results in cross-resistance to multiple inhibitors, 5 '-methoxyhydnocarpin could be used as a synergist to increase efficacy of several present day antibiotics.

\section{Isolation of Antifungal Extracts}

Once a species has been identified as a potential lead, isolation of an antifungal phytochemical from a selected plant species conventionally involves bioas- say-guided isolation (Figure 2), beginning with the preparation of a crude extract. This involves taking all, or selected, plant parts and grinding them in a blender, or similar device, in the presence of a suitable solvent [e.g. 19]. In some cases, the resulting slurry is exposed to sonication to help rupture the plant cells and to release and solubilize compounds [e.g. 21]. The crude extract is separated from cell debris by filtration and tested for antifungal activity as described below.

\section{Disk Diffusion Assays}

Once a crude extract has been prepared, its potential anti-microbial activity may be tested through a simple and reliable test, such as the disk diffusion assay. This assay requires little in terms of material, provides robust and reliable results, and can be used to test a diversity of microbes. For this test, an agar plate must first be inoculated with the microbe of interest. A small absorbent paper disk is impregnated with the plant extract to be tested and then placed onto the surface of the agar. The extract will diffuse into the agar medium surrounding the disk, where any antimicrobial effects will interfere with growth of the microbe. The concentration of the extract will be highest near the paper disk, and decrease radially to a point where the concentration is no longer inhibitory. After incubation, inhibitory activity is observed as a region around the disk where no growth has occurred, termed the zone of inhibition. The size of the zone of inhibition is dependent on the inhibitory compound's ability to diffuse through the medium, its inhibitory characteristics and abundance in the crude extract. The zone of inhibition can be compared to a similarly prepared disc containing a known inhibitor and to a negative control disk that is prepared with the solvent carrier [15]. This technique has been used in the past to identify antifungal effects as well as other antimicrobial activity in crude extracts from diverse plant species $[5,6,12,15,18,21,22,23,24]$. The technique may be of limited use if inhibitory compounds do not adequately diffuse through the agar medium and the zone of inhibition is obscured by the paper disk. Although this test does not reveal the mechanism by which extracts inhibit growth, it can quickly determine whether a plant extract is active against strains that are resistant to known antibiotics [23].

\section{Identification of Antifungal Constituents}

Conventional bioassay-guided fractionation is most often used to isolate and identify unknown antifungal compound(s) [e.g. 12]. This process involves separating compounds based on extraction of fractions from the plant material based on a series of solvents of increasing polarity, such as hexane, ethyl acetate 
and methanol. The fractions are tested for activity and the active fraction is further separated by column chromatography. Multiple different fractions are collected and each is subjected to further antimicrobial bioassays. If deemed active, a particular fraction is further resolved by preparative HPLC until a single active compound is isolated $[12,24]$. The structure of the pure compound is then identified by advanced spectroscopic techniques. Recently, high throughput metabolomics methods such as HPLC-MS/MS assays have been developed that can be used to identify members of known families of compounds in plants by matching fragmentation patterns to libraries of known compounds.

\section{Metabolic Assays}

After isolating a compound and determining that it has antifungal activity, several forms of assays may be useful to elucidate the compound's cellular target(s). Most compounds will interact with and inactivate a specific enzyme, pathway, or stage in a pathogen's life cycle.Provided the drug interferes with the pathogenic organism's growth, but does not substantially interfere with the host, any essential component of the pathogen can be tested as a potential target site. The goal of a metabolic assay is to test a compound for these potential effects on a specific pathway, and each assay relies on an in vitro approximation of the pathway examined. Such assays can take multiple formats, such as the substrate conversion system, DNA polymerization or nucleotide biosynthesis.

For substrate conversion assays, the test compound is mixed with an enzyme of interest, and the assay is based on colourimetric, fluorescent, or radiometric monitoring of the catalytic process. The binding of the test compound to the enzyme may reduce the enzyme's ability to catalyze the substrate-to-product reaction, and therefore alters the reaction kinetics in comparison to a system without the test compound. Colour or fluorescence signals can be monitored spectrophotometrically in this assay, and radiometric effects can be detected by scintillation counting or using film or digital imaging techniques.

To examine DNA polymerization, nucleotides labeled with radioactive isotopes have been used in the past as substrate components. A proxy of DNA replication in cells may use the polymerase chainreaction (PCR). Under ideal circumstances, the amount of the DNA sequence of interest (the "amplicon") doubles during each cycle. However, the addition of a compound that interferes with DNA polymerization would inhibit amplification, and diminishes the amount of newly synthesized DNA [25]. The inhibitor may act on any component of the
PCR process, including Taq polymerase or the DNA template.

Recently, a modification of the PCR procedure has been developed to allow for continuous quantification of the amount of DNA synthesized during the reaction [26]. This method of real-time PCR (RTPCR) presents a simple and precise approach for measuring the quantity of amplicon produced and the efficiency of the reaction. By comparing the rates at which the amplicon concentration increases in different reactions, a precise measure of the inhibitory effects of an extract can be calculated.

Compounds that inhibit DNA polymerization may be genotoxic to a wide variety of organisms, however, and therefore of little use as antimicrobials geared towards medicines taken internally. However, differences in the base composition of some microbial genomes, or in the polymerase enzyme itself, may provide specific targets [25]. Furthermore, such compounds may have applications as topical treatments or in preventing materials spoilage.

The activity of the Ribonucleotide Reductase enzyme (RNR), which is essential in many organisms for the conversion of RNA precursors into DNA precursors that are used in the replication and repair of DNA synthesis, can be tested using radioactive tracers. RNR converts the ribonucleoside diphosphate into deoxyribonucleoside diphosphate, which is subsequently phosphorylated and incorporated into DNA by DNA polymerase. RNR catalytic activity can thus be estimated by monitoring the amount of a suitable radioactively labeled substrate that is incorporated into DNA using scintillation counting. If the enzyme is inhibited by the addition of a specific inhibitor of RNR, little or no DNA polymerization will occur and scintillation counts will be low [27]. Resveratrol, a chemical extracted from red grape skins, was found to target RNR using this method [28]. Resveratrol was found to be more effective than hydroxyurea, p-propoxyphenol, and the clinically-used hydroxyanisole. As this compound is found in grapes, which are Generally Regarded As Safe (GRAS), it or similar compounds may have potential as inhibitors of a pathogen's RNR function.

In order to examine activity on a specific enzyme more effectively, a molecule can be sought which interacts with a specific protein, as was done for the human insulin receptor (IR) by Salituro et al. (2001) [29]. By using a series of screens with intact hamster cells containing the human IR protein, they were able to screen a library of small molecules that bind to the IR target. If the extract interacted with the IR, it would trigger the phosphorylation and activation of a tyrosine kinase, which in turn would show activity on the substrate polyGlu:Tyr (4:1). In their experiment, the fungal-derived small molecule demethylasterriquinone B-1 was found to activate the 
IR complex. Such a technique may prove useful to search extensive chemical lists for specifically targeted effects.

While these strategies can be used to test many extracts for possible effects in specific pathways, a significant limitation remains that each extract has to be tested separately for its activity on different pathways. This generally translates into the investigation of one pathway at a time. When one considers the large number of pathways in the cell that may be affected by any given chemical, the number of chemicals which can be isolated from a single plant, and the number of plants that may be candidates for research, the potential economic and labor cost of these investigations quickly surpasses that which is practically available. Without more efficient techniques, research would be limited to a small subset of the available candidates, significantly restricting discovery of alternative treatments. Similarly, for extracts that have multiple effects, many of these effects could also be overlooked. As a further limitation, many of these tests are done in vitro, and may not apply to living cells/organisms. Factors such as intracellular localization and concentration cannot be accounted for. Thus, though in vitro effects may be demonstrated, these effects may not have the chance to occur within a cellular environment.

\section{Modern Techniques in Drug Discovery}

To improve the speed and efficiency of the screening process, high-throughput techniques have been developed that examine many potential target sites for a given extract in a single experiment. Such techniques are designed to identify effects on several biochemical pathways. Two such techniques are DNA microarray and gene deletion array (GDA) analyses. While reviewing these large-scale analyses, it should be kept in mind that an increase in throughput comes with an inherent risk. The less time spent on a given test, the higher the risk for false positives and negatives. Yet the value of screening large numbers by high-throughput analysis of possible source candidates for drug research cannot be overlooked.

\section{Microarray Analysis}

Differential expression of multiple genes with known and unknown functions may be used to evaluate the mode of action of antifungals. The idea is that genes, or gene products, which are directly or indirectly interacting with a bioactive compound, are differentially expressed once the cell is challenged with a biologically-active compound. Traditionally, gene expression has been evaluated by analysing the amount of a specific messenger RNA (mRNA) present in the cell through a method called Northern analysis. mRNA is synthesized through transcription from a given gene in accordance with molecular interactions within the cell that regulate whether transcription should remain the same, increase or decrease. In Northern analysis, total mRNA is size fractionated by gel electrophoresis and then immobilized onto membranes. Labeled DNA probes are subsequently used to hybridize and quantify the abundance of a specific target mRNA. Although a very precise method for measuring the mRNA levels of a gene, Northern analysis is time consuming. Recently, a large-scale probe-based gene expression analysis technique called microarray analysis has been developed which uses microchip technology to miniaturize the probe-mRNA interaction and therefore maximizes the number of genes that can be monitored simultaneously.

Microarrays are constructed by binding a series of probes to a chip, thus generating a platform to detect an array of target genes. The probes are generally composed of fluorescent-labeled complementary DNA (cDNA) molecules derived from messenger RNA (mRNA). They bind to complementary short sequences of target DNAs from those genes that are arrayed on the chip. Total mRNA is isolated from cells that are challenged by an antifungal compound. As a control, mRNA is isolated from cells that are untreated. The experimental and control mRNAs are separately converted into cDNA through the action of reverse transcriptase and differentially labeled with fluorescent tags. The cDNAs are then mixed together and applied to the surface of the chips. The hybridization of the probes to the target DNA spots are then visualized and quantified by a scanning fluorescence array reader. Analysis of the data can indicate whether transcription of any given gene is altered under the experimental conditions. The interpretation of the data can in turn be used to reveal information about the target site and the mechanism of the action of the antifungal. Depending on the mode of action of an antifungal, if a given gene product is a target site of the antifungal then it might be expected that the treatment of the cells with that antifungal would result in a significant change in the expression of that particular gene. In this way the cell may compensate for perturbations in particular pathways. To investigate antifungal compounds, chips arrayed with all Open Reading Frames (ORFs, i.e. putative protein coding genes) of the brewer's yeast, Saccharomyces cerevisiae, are often used. The simple life cycle, short duplication time and the welldeveloped genetics associated with this yeast have made it an ideal choice for follow up experiments.

Protein Microarrays, in early development stages, can also be constructed using proteins as the targets, to test for the binding of small molecules [30]. This would allow for a quick determination of a chemic- 
al's binding site within a cell, and would also reveal if the chemical in question binds to multiple protein targets. Within a single test, and on a single chip, hundreds of thousands of binding assays can take place, permitting the quick identification of a drug's effect.

A significant limitation of microarrays is the interpretation of the large amount of data that it produces. Variation in gene expression between different trials together with a high rate of false positives can significantly complicate the interpretation of the data. As a result, various statistical tools have been developed to help with the analysis of microarray data. To date, however, the interpretation of microarray data remains a significant challenge for biologists as well as bioinformaticians.

Another significant drawback of the microarray is that it is based on an indirect correlation; a positive correlation does not necessarily specify a direct interaction. An increase in expression for gene "a" might indicate that the antifungal is deactivating the gene product " $\mathrm{A}$ " and as a response, the cell is producing more of "A". Alternatively, it is as likely that the antifungal is interacting with gene product " $\mathrm{B}$ " which, in turn, has an effect on genes "a, c, d, e...". Such a drawback of microarray analysis might be compensated by a more direct method that targets the activity of a gene product and not its expression (see below).

\section{Gene Deletion Array Analysis}

The Gene Deletion Array (GDA) analysis is a highthroughput in vivo technique that can be used to elucidate the mechanism by which a bioactive compound affects the cell. It works on a basis similar to that of Synthetic Genetic Array (SGA) analysis. The assumption in SGA analysis is that in a cell there exist multiple overlapping pathways leading to a single outcome [31]. The inactivation of one pathway may not have a significant effect on the growth of the cell. However when the first mutation is combined with the inactivation of a second overlapping pathway, this can lead to a growth defect. This growth defect is termed "synthetic sick phenotype". In SGA, the inactivation of the second pathway is generated via a specific gene deletion. In GDA, however, the synthetic sick phenotype results from the combination of a specific gene deletion and a chemical interaction. GDA can be used, therefore, to study the pathway and/or components affected by a specific chemical.

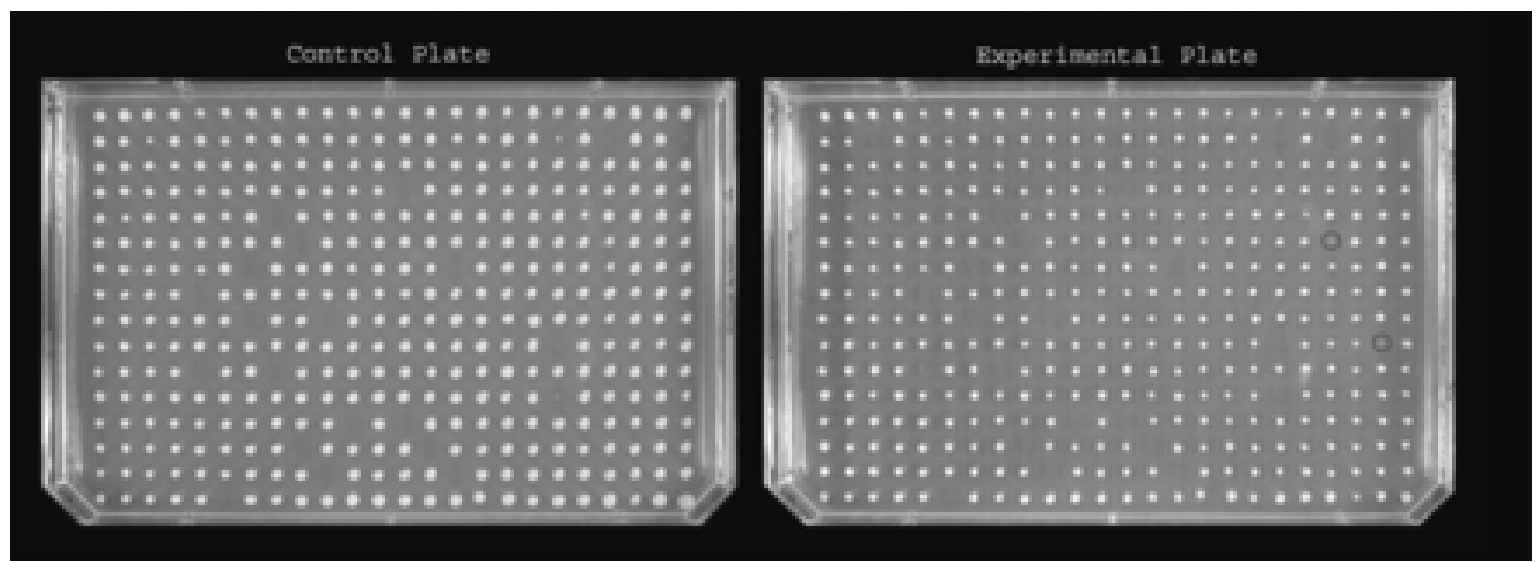

Figure 3: Images Taken of Two Sample Plates from GDA Analysis, Testing for the Effects of an Extract of Echinaceae on S. cerevisiae Gene Knock-out Mutants. While most of the Colonies show Comparable Growth, some Knockout Mutant Colonies do not Grow Substantially in the presence of the Extract (circled Colonies on Experimental Plate). The Analysis of the Specific Gene Mutations in "Supersensitive" Colonies provides insight into the Biochemical and Genetic Bases of the inhibitor mode-of-Action

Large-scale GDA analysis uses an array of yeast mutant strains, each strain having a single gene knocked out (Figure 3). In the case of $S$. cerevisiae, there are approximately 4700 (of $\sim 6000$ ) genes that can be deleted without affecting the viability of the cell. To determine the mechanism by which a plant extract affects yeast growth, an equal amount of inoculum from each mutant strain is transferred from a master plate of gene knock-out strains to a plate containing a concentration of the plant extract that is slightly inhibitory to the growth of yeast. A second plate, with no inhibitor added, is also inoculated with all yeast mutants as a control. The inoculation procedure is usually done using an automated pinning robot. After incubation and colonies are observed on the plates, the size of each knock-out colony on the experimental (with inhibitor) and control (no inhibitor) plates is estimated. Any significant growth reduction of a specific mutant colony on the plate containing the target plant extract is scored as a potential hit. Colony size is tightly correlated to number of cells in a colony and, thus, cell-division rates [32]. Once such colonies are identified, increased sensitivity to the compound can be verified by analysis of 
the Minimum Inhibitory Concentration (MIC), and the function of the deleted genes and the pathways in which they are involved can be used to shed light on the mode of action by the plant extract. As most pathways involve multiple different gene products, there should be multiple hits on the same pathway. If genes from two independent pathways show reduced growth, it will be interpreted that the extract affects both pathways.

A significant limitation of GDA analysis is its relatively high rate of false positives. To minimize these, multiple replicates must be conducted, which results in the consumption of additional material that is not always available. GDA data analysis provides another difficulty. Comparing the growth of individual colonies by eye, particularly if the colonies show unequal growth within or between plates, can be tedious and unreliable. As a result, digital imaging software that analyses colony size and growth patterns can significantly improve the efficiency of analysis. An automated system can compensate for the universally reduced growth on a plate containing sub-MIC levels of extract as compared to the control plate. Statistical analysis can then be performed to evaluate the growth of a specific colony in relation to the average growth on both control and experimental plates.

Another key difficulty with GDA lies in allocating genes to specific pathways within the cell. At this time, many genes have unknown functions. Many others have multiple functions within the cell, and could perform tasks for more than one pathway. For example, a known DNA polymerase could be involved in DNA synthesis, DNA repair, or both. Likewise, while RNR catalyzes the formation of DNA precursors, it may have other roles in the cell, including spindle pole nucleation [33]. If the genes shown to interact with the extract do not have a clear function, have more than a single role to play in the cell, or appear unrelated, the picture created by GDA may very quickly become unclear.

\section{High Throughput Screening}

In many cases, pharmaceutical companies utilize high-throughput screening to determine biologically active fractions or mechanisms of antifungal activity. With these emerging technologies, pharmaceutical companies are now returning to the study of plant derived drugs as 10,000 to 100,000 extracts can be screened per day. Online HPLC combines HPLC fractionation with biochemical assays and spectral analysis such as GCMS [7]. Currently, systems that examine drug-cell interactions exist. For example, in an attempt to identify compounds that reduce diseases such as breast cancer and osteoporosis, a plant extract library containing 9888 different extracts was examined for potential activities against estrogen receptors. Of the 9888 extracts analysed, roughly 1100 hits were observed to interact with the estrogen receptor [7]. Therefore, only $11.1 \%$ of all extracts could be examined, reducing the amount of time spent on studying inactive fractions. This technology could be implemented to screen for new antifungal drugs by screening antifungal activity against a library of drug-resistant, drug-sensitive and opportunistic fungal strains. In addition, a specific antifungal mechanism may be identified for study using high throughput screening. Such a biochemical assay could be developed as described above, which would allow determination of extracts active against fungal specific pathways, for example, cell wall (chitin) biosynthesis.

\section{Conclusion}

While the importance and usefulness of many traditional medicines cannot be denied, only recently have the required technologies become available to evaluate these remedies and their effects in an efficient and comprehensive manner. By examining the past use of a given plant in the treatment of infections, phytochemicals can be identified that inhibit fungal pathogens. Moreover, with modern high-throughput technologies such as online HPLC, DNA microarrays, GDA, and advances in robotics allowing test automation, the exact effects of a given extract, as well as the chemical or chemicals at work can also be determined. Identification of these chemicals provides leads for the synthesis of analogs and development of novel antifungal drugs. Alternatively, identification of active principles in traditional medicines can also lead to standardization and quality control of these materials. They can then be more quickly registered under the "traditional use" guidelines as lower cost natural health products which are effective in both developing and developed countries.

\section{References}

1. Alexander, B.D. and Perfect J.R. 1997. Antifungal resistance trends towards the year 2000. Implications for therapy and new approaches. Drugs. 54: 657-678.

2. Arnason, J.T., Hebda, R., and Johns, T. 1981. Use of plants for food and medicine by native peoples of eastern Canada. Canadian Journal of Botany. 59: 2189-2325.

3. Anderson, J.B. 2005. Evolution of antifungal drug resistance: mechanisms and pathogen fitness. Nature Reviews. 3: 547556. 
4. Soejarto D.D., Fong, H.H.S., Tan, G.T., et al. 2005. Ethnobotany/ethnopharmacology and mass bioprospecting: Issues on intellectual property and benefit-sharing. Journal of Ethnopharmacology. 100: 15-22.

5. Jones, N.P., Arnason, J.T., Abou-Zaid, M., Akpagana, K., Sanchez-Vindas, P., and Smith, M.L. 2000. Antifungal activity of extracts from medicinal plants used by First Nations Peoples of eastern Canada. Journal of Ethnopharmacology. 73: 191-198.

6. Omar, S., Lemonnier, B., Jones, N., Ficker, C., Smith, M.L., Neema, C., Towers, G.H.N., Goel, K., and Arnason, J.T. 2000. Antimicrobial activity of extracts of eastern North America hardwood trees and relation to traditional medicine. Journal of Ethnopharmacology.73: 161-170.

7. Van Elswijk, D.A. and Irth, H. 2003. Analytical tools for the detection and characterization of biologically active compounds from nature. Phytochemisty Reviews. 1: 427-439.

8. Treyvaud-Amiguet, V. 2005 Ethnobotanical and phytochemical investigation of Central American flora. Ph. D. Thesis. University of Ottawa, Ottawa, Ontario, Canada.

9. Brun, S., Berges, T., Poupard, P., Vauzelle-Moreau, C., Renier, G., Chabasse, D., Bouchara, J. P. (2004).Â Mechanisms of azole resistance in petite mutants of Candida Glabrata. Antimicrobial Agents and Chemotherapy. 48: 17881796.

10. Jensen-Pergakes, K.L., Kennedy, M.A., Lees, N.D., Baybuch, R., Koegel, C., and Bard, M. 1998. Sequencing, disruption, and characterization of the Candida albicans sterol methyltransferase (ERG6) gene: drug susceptibility studies in erg6 mutants. Antimicrobial Agents and Chemotherapy. 42:1160-1167.

11. Merali, S., Binns, S., Paulin-Levasseur, M., Ficker, C., Smith, M., Baum, B., Brovelli, E., and Arnason, J.T. 2003. Antifungal and anti-inflammatory activity of the genus Echinacea. Pharmaceutical Biology. 41: 412-420.

12. Ficker, C., Smith, M.L., Akpagana, K., Gbeassor, M., Zhang, J., Durst, T., R. Assabgui, R., and Arnason, J.T. 2003 b. Bioassay-guided isolation and identification of antifungal compounds from ginger. Phytotherapy Research. 17: 897-902.

13. Bennett, J.W., and Klich, M. 2003. Mycotoxins. Clinical Microbiology Reviews. 16:497-516.

14. Hof, H. 2001. Critical annotations to the use of azole antifungals for plant protection. Antimicrobial agents and chemotherapy. 45: 2987-2990.

15. Ficker, C.E., Smith, M.L., Susuarti, S., Leaman, D.J., Irawati, C., and Arnason, J.T. 2003. Inhibition of human pathogenic fungi by members of Zingiberaceae used by the Kenyah (Indonesian Borneo). Journal of Ethnopharmacology. 85: 289-293.

16. Chandrasekaran, M., and Venkatesalu, V. 2004. Antibacterial and antifungal activity of Syzygium jambolanum seeds. Journal of Ethnopharmacology. 91: 105-108.

17. Cowan, M.M. 1999. Plant products as antimicrobial agents. Clinical Microbiology Reviews. 12:564-582.

18. Binns, S.E., Purgina, B., Bergeron, C., Smith, M.L., Ball, L., Baum, B.R. and Arnason, J.T. 2000. Light-mediated antifungal activity of Echinacea extracts. Planta Medica. 66:241-244.

19. Lopes, N.P., Kato, M.J., and Yoshida, M. 1999. Antifungal constituents from roots of Virola surnamensis. Phytochemistry. 51: 29-33.

20. Stermitz, F.R., Lorenz, P., Tawara, J.N., Zenewicz, L.A., and Lewis, K. 2000. Synergy in a medicinal plant: antimicrobial action of berberine potentiated by 5'-methoxyhydnocarpin, a multidrug pump inhibitor. Proceedings of the National Academy of Science. 97: 1433-1437.

21. Bafi-Yeboa, N.F.A., Arnason, J.T., Baker, J., and Smith, M.L. 2005. Antifungal constituents of Northern prickly ash, Zanthoxylum americanum Mill. Phytomedicine. 12: 370-377.

22. Binns, S.E., Purgina, B., Bergeron, C., Smith, M.L., Ball, L., Baum, B.R. and Brun, S., Berge, T., Poupard, P., VauzelleMoreau, C., Renier, G., Chabasse, D., and Bouchara, Jean-Philippe. 2004. Mechanisms of azole resistance in petite mutants of Candida glabrata. Antimicrobial agents and chemotherapy. 48:1788-1796.

23. Ficker, C.E., Arnason, J.T., Vindas, P.S., Alvarez, L.P., Akpagana, K., Gbeassor, M., De Souza, C., and Smith, M.L. 2003a. Inhibition of human pathogenic fungi of ethnobotanically selected plant extracts. Mycoses. 46: 29-37.

24. Yang, X., Summerhurst, D.K., Koval, S.F., Ficker, C., Smith, M.L. and Bernards, M.A. 2001. Isolation of an antimicrobial compound from Impatiens balsamina L. using bioassay-guided fractionation. Phytotherapy Research. 15: 676-680.

25. Smith, M.L. Gregory, P., Bafi-Yeboa, N.F.A. and Arnason, J.T. 2004. Inhibition of DNA polymerization and antifungal specificity of furanocoumarins present in traditional medicines. Phytochemistry and Photobiology. 79: 506-509.

26. Stenman, J., Finne, P., Stahls, A., Grenman, R., Stenman, U. H., Palotie, A., Orpana, A. 1999. Accurate determination of relative messenger RNA levels by RT-PCR. Nature Biotechnology. 17: 720-722

27. Jong, A. Y., Yu, K., Zhou, B., Frgala, T., Reynolds, C. P., Yen, Y. 1999. A simple and sensitive ribonucleotide reductase assay. Journal of Biomedical Science. 5: 62-68.

28. Fontecave, M., Lepoivre, M., Elleingand, E., Gerez, C., and Guittet, O. 1998. Resveratrol, a remarkable inhibitor of ribonucleotide reductase. FEBS Letters. 421: 277-279.

29. Salituro, G. M., Pelaez, F., and Zhang, B.B. 2001. Discovery of a small molecule insulin receptor activator. Recent Progress in Hormone Research. 56: 107-126.

30. MacBeath, G., and Schreiber, S.L. 2000. Printing proteins as microarraysfor high-throughput function determination. Science. 289: 1760-1763.

31. Tong, A.H.Y., Lesage, G., Bader, G.D., et al 2004. Global mapping of the yeast genetic interaction network. Science. 303: $808-813$. 
32. Xu, J., Vilgalys, R., and Mitchell, T.G. 1998. Colony size can be used to determine the MIC of fluconazole for pathogenic yeasts. Journal of Clinical Microbiology. 36: 2383-2385.

33. Takada, S., Shibata, T., Hiraoka, Y., and Masuda, H. 2000.Identification of Ribonucleotide Reductase Protein R1 as an Activator of Microtubule Nucleation in Xenopus Egg Mitotic Extracts.Molecular Biology of the Cell. 11: 4173 4187.

\section{About the Authors}

Matthew G. M. Jessulat

Research using yeast Gene Deletion Arrays to understand pathways involving genetic recombination and antifungal inhibitors.

\section{Robert Phillip Smith}

Research into nonself recognition and protein aggregation in fungi.

Nadereh H. Mir-Rashed

Carleton University, Canada

Dr Ashkan Golshani

Carleton University, Canada

Dr John Thor Arnason

University of Ottawa, Canada

Dr. Myron L. Smith

Carleton University, Canada 
THE INTERNATIONAL JOURNAL OF TECHNOLOGY, KNOWLEDGE AND SOCIETY

EDITORS

Bill Cope, University of Illinois, Urbana-Champaign, USA.

Mary Kalantzis, University of Illinois, Urbana-Champaign, USA.

Amareswar Gala, Australian National University, Australia.

EDITORIAL ADVISORY BOARD

Darin Barney, McGill University, Montreal, Quebec, Canada.

Amy Besnoy, Copley University, University of San Diego, CA, USA.

Marcus Breen, Northeastern University, Boston, USA.

G.K. Chadha, Jawahrlal Nehru University, India.

Simon Cooper, Monash University, Australia.

Bill Dutton, University of Oxford, United Kingdom.

David Hakken, University of Indiana, Bloomington, Indiana, USA.

Michele Knobel, Montclair State University, New Jersey, USA.

Chris Scanlon, RMIT University, Melbourne, Australia.

Jeannette Shaffer, Edtech Leaders, VA, USA.

Ravi S. Sharma, Nanyang Technological University, Singapore.

Robin Stanton, Australian National University, Canberra, Australia.

Telle Whitney, Anita Borg Institute for Women and Technology.

Monica Zuccarini, Università di Napoli, Italy.

Please visit the Journal website at http://www.Technology-Journal.com for further information:

- $\quad$ ABOUT the Journal including Scope and Concerns, Editors, Advisory Board, Associate Editors and Journal Profile

- FOR AUTHORS including Publishing Policy, Submission Guidelines, Peer Review Process and Publishing Agreement

\section{SUBSCRIPTIONS}

The Journal offers individual and institutional subscriptions. For further information please visit http://ijt.cgpublisher.com/subscriptions.html. Inquiries can be directed to subscriptions@commongroundpublishing.com

INQUIRIES

Email: cg-support@commongroundpublishing.com 